Website: http://jsci.utq.edu.iq Email: utjsci@utq.edu.iq دراسة فعالية قلويدات نبات عين البزون Catharanthus roseus (L.) G.Don ضد نوعين من الخطوط الخلوية السرطانية

ليلى ناصر حرب

$$
\text { عبد الأمير عبد الله يعقوب }
$$

علي عبود شريف

قسم علوم الحباة- كلية التربية- جامعة البصرة

\begin{abstract}
الخلاصة
درست الفعالية ضد السرطانية لقلويدات نبات عين البزون Catharanthus roseus (L.) G.Don ضد نوعين من الخطوط الخلوية السرطانية وهما الخط Hep-2 لخلايا سرطان الحنجرة البشري, والخط

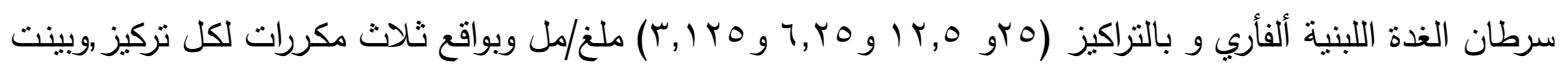
النتائج أن الستخلص القلويدي اظهر فعالية عاليةضد الخط

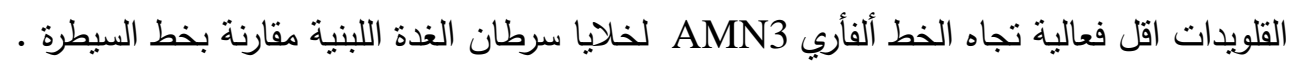
الكلمات المفتاحية : قلويدات عين البزون, الفعالية الضد السرطانية . لإنان
\end{abstract}

natural products استخدمت النواتج الطبيعية

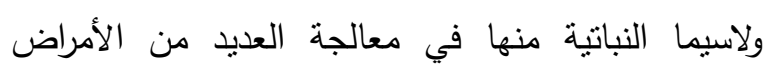

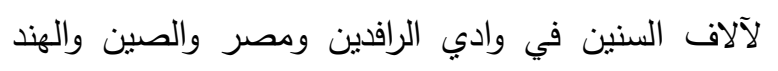

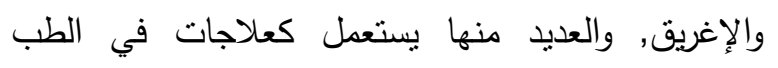

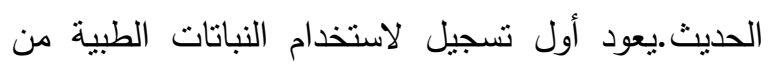

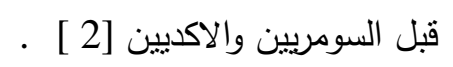
استخدم هذا النبات من قبل العشابين الأوربيين لعلاج

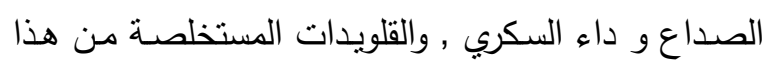

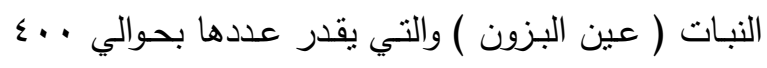
مركب قلويدي ذات فعالية ضد سرطانية وتعد صنفا جديدا

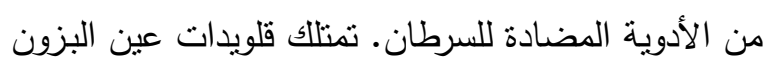

ينتمي الجنس Catharanthus G.Don إلى عائلـة الدفلـة Apocynaceae , واصلـ اسم الجنس هو

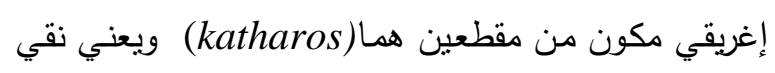

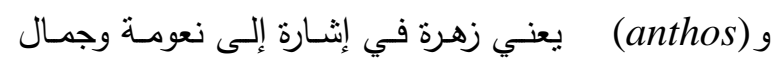

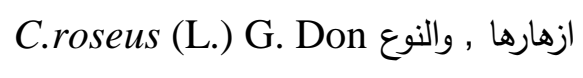
يتقد بأنه ينمو بصورة طبيعية (= Vinca rosea L.)

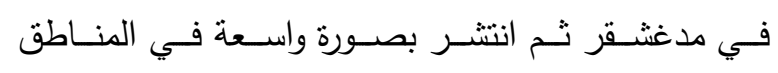

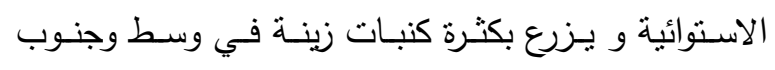

العراق.11 [1 
Bismuth المحلول A: وزن 7, •غم من نترات البزموث subnitrate الهيدروكلوريك المركز وخفف بعدها بإضافة ـ ـ مل من

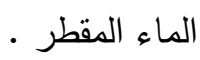

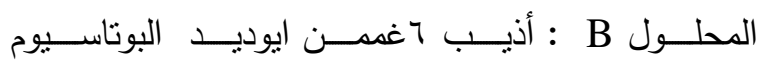
مجرج Potassium iodide

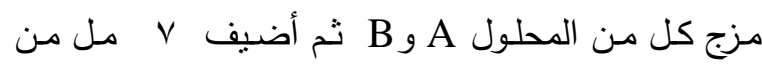

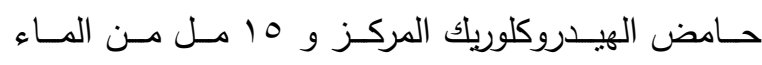

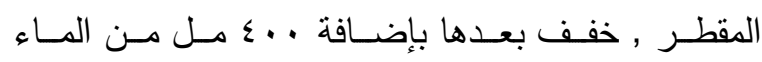
المقطر [7]. r- كاشف ماير : حضر بإذابة م, با اغم من كلوريد الزئبق

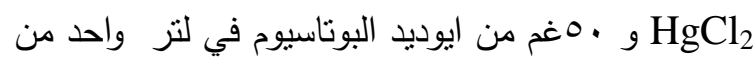

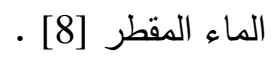

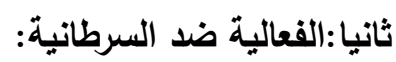
أ- - ت تهيئة خطوط الخلايا:

تم الحصول على نوعين من الخطوط الخلوية السرطانية

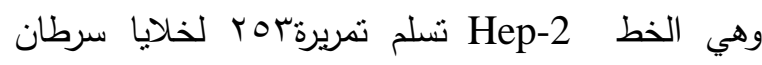
الحنجرة البشري ، والخط AMN3 لخلايا سرطانة الغدة اللبنية فأري.7 من المركز العراقي لبحوث الخدوث السرطان

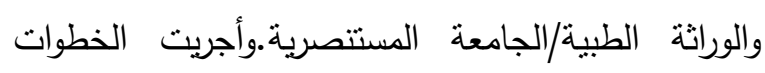

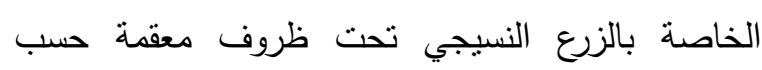
طريقة [9] وكالاتي: أضيفr مل من محلول التربسين- فرسين المحضر الى وعاء الزرع النسيجي حجم •0 سمّ الحاوي على الخلايا

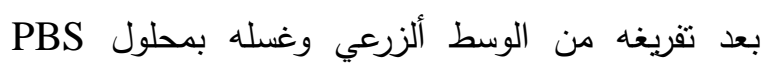

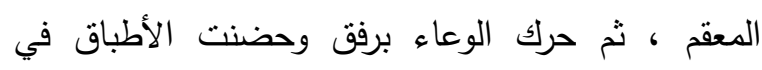

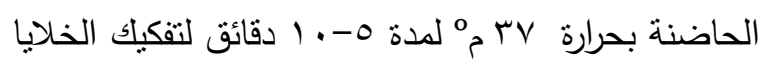

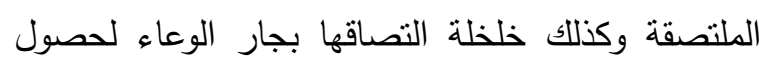
على خلايا منفردة.
فعالية ضد سرطانية العديد من الأمراض السرطانية مثل

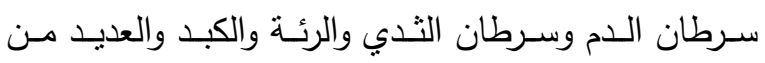
الأورام السرطانية الصلبة [4] ـ[3] . درست الفعالية الطبية لهذه القلويدات في بدايـة عام 1970 واستخدمت الاردية أيضا ضد الأورام السرطانية لأكثر من ثلاثثن سنة مضت عات

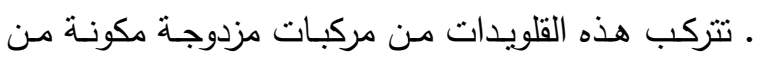
انويه من الاندول ثنائي النميؤ dihydroindole المرتبطة

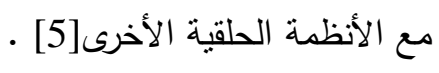
أولا:استخلاص القلويدات المبات العمل

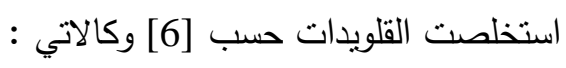

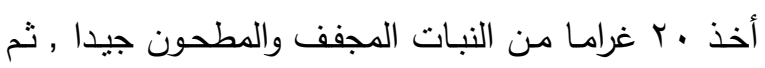
استخلصت القلويدات بإضافة . 1\% من حامض ألخليك

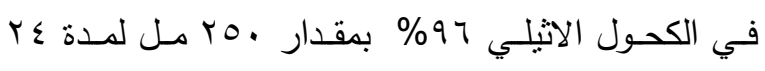

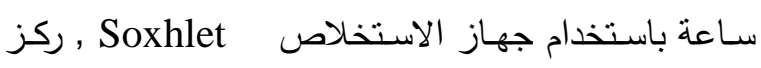

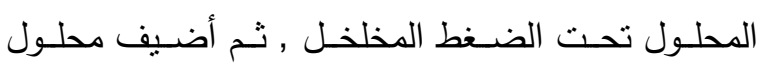
هيدروكسيد الامونيوم المركز بشكل قطرات إلى المحلول

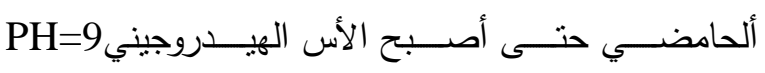
وأضيف أليه 100 مل من الكلوروفورم ورج عدة مرات ثم الخي

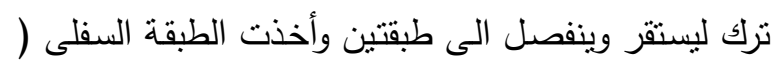
طبقة الكلوروفورم ) مذابة فيها القلويدات , ركز المحلول ولئل

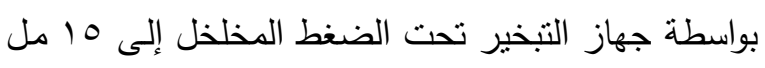

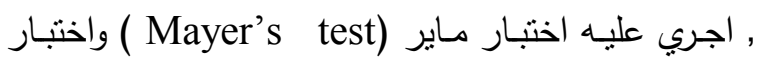
دراكندروف (Dragndroff 's test) للمحلول المذكور

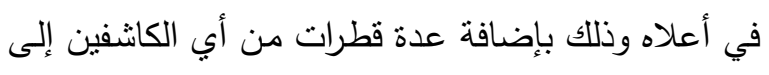

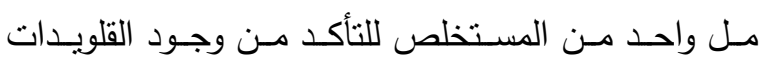
وأعطى راسب ابيض او راسب اصفر عند إضافة قطرات كل من كاثف ماير و دراكندروف على التوالي , حضر الثر الكاثفين كالأتي :- كلئ ماير 1- كاثف دراكندروف : هذا الكاثف مكون من محلولين 


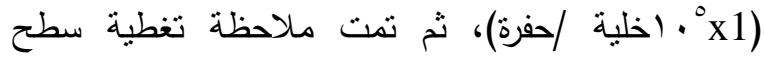
الطبق بورق لاصق شفاف معتم وحرك الطبق بلطف

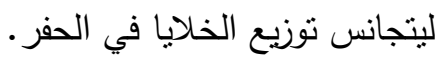
تركت الأطباق في الحاضنة بحرارة VT مُ لمد لمدة تراوحت

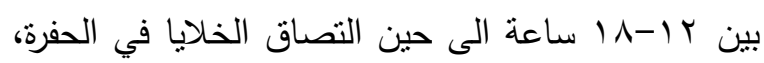

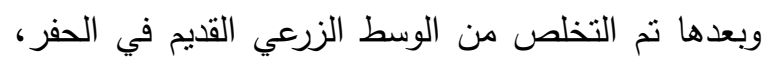

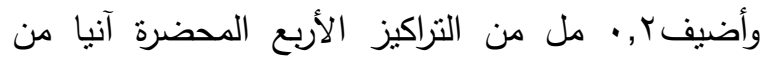
المستخلص القلويدي باستعمال الوسط الخالي من الكصل وهي (SFM) وبواقع ثلاث مكررات لكل تركيز • كما تم عمل ثناثة

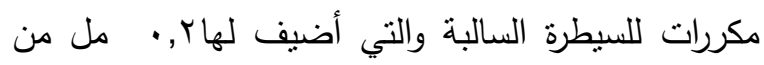

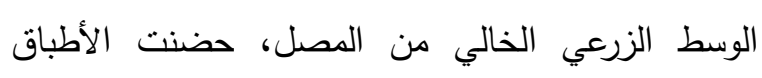

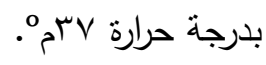

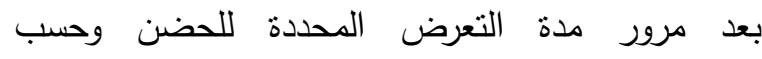

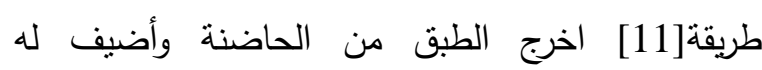

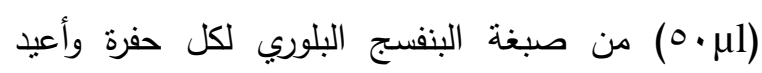

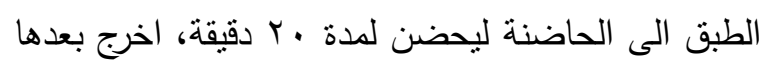

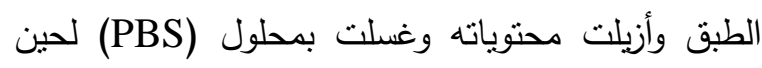

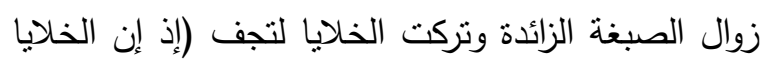

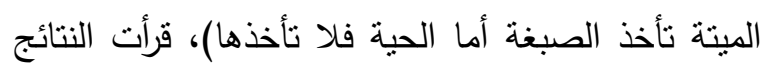
باستخدام جهاز المطياف الضوئي بأطباق المعايرة الدقيقة

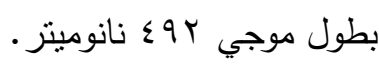
تم تحديد معدل تنثيط النمو للخلايا السرطانية على وفق المعادلة المشار إليها في[12] من خلال تحويل قيم

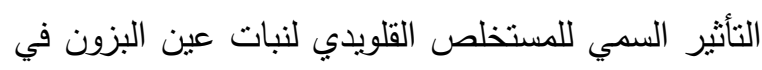

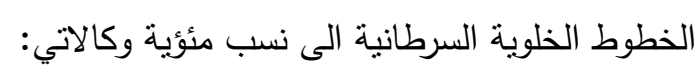
Inhibition Rate(IR)\%= (A-B/A) x 100 النسبة المئوية لمعدل التثبيط : IR A : الكثافة الضوئية للسيطرة B : الكثافة الضوئية لمجموعة الاختبار : A

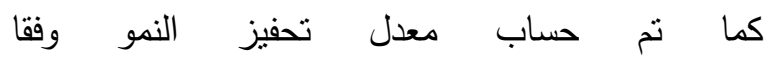
(Chumchalova and Samarda, 2003)」
عدت الخلايا الحية على وفق [10] لكل نوع من الخلايا باستخدام صبغة التريبان الزرقاء(Trypan blue) ، إذ إذ تأخذ الخلايا الميتة الصبغة ببضع ثوان مما يجعلها سهلة الترنة

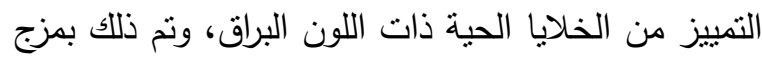

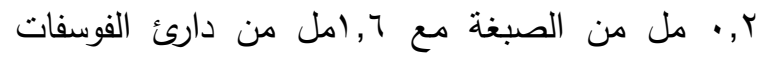

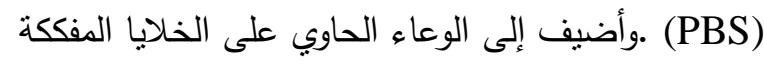

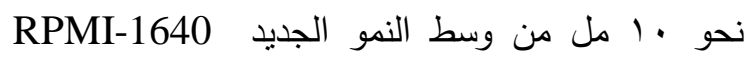

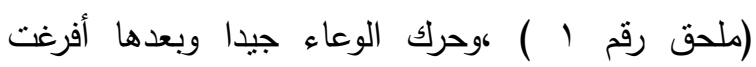
محتوياته على الوسط الغذائي الجديد مع الخلايا إلى وعاء الزاء

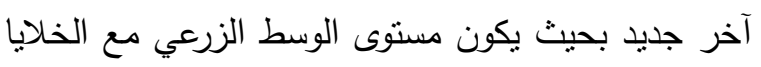

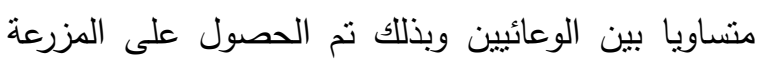

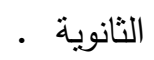

حضنت الأوعية بحرارة VT مُ بعد أن كتب عليها

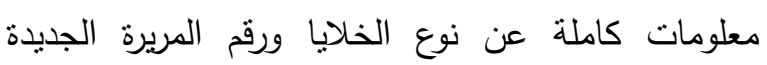
New Passage

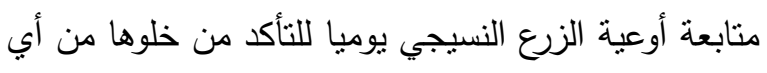

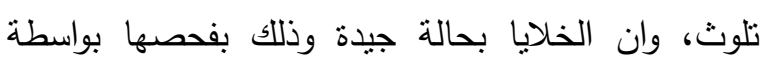
- المجهر مقلوب الطور (Inverted Microscope) وعندمااصبحت الخلايا ذات نمو جيد متمثل بنكوين طبقة أحادية كاملة من الخلايا (Confluent monolayer) تكون الخلايا بذلك جاهزة للاستعمال.

\section{ب -اختبار السمية الخلوية للمستخلص القلويدي في} نمو الخطوط الخلوية السرطانية:

جهز عالق الخلايا عن طريق معاملة وعاء

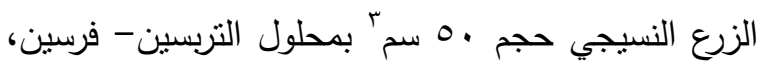

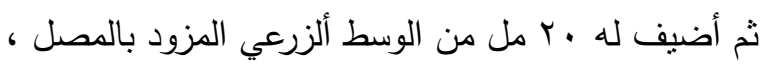

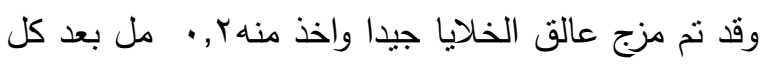
مزجة إلى كل حفرة من حفر طبق الزرع النسيجي ذي الني القعر المسطح (96-Microtiter plates) باستعمال ماصة أوتوماتيكية دقيقة، إذ احتوت كل حفرة على بلى 
(OD) لخلايا السيطرة و المعاملة ( جدول رقم () وهذا (OD)

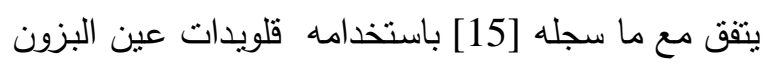
Vinca alkaloid J82 cell line السرطانية للمثانة وسجل ايضآ بأن هناك تباينا قويا في قيم الكنافة الضوئية

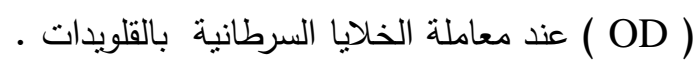
عند تعريض الخلايا والأنسجة لقلويدات نبات عين البزون

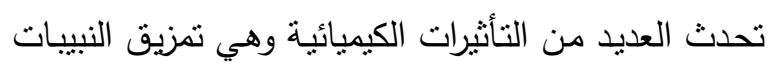
الاققيقة Micro tubules وتثبيط تصنيع البروتينات والأحماض الامينية , وتزيد من تركيز الكلوناثايون المؤكسد الئند

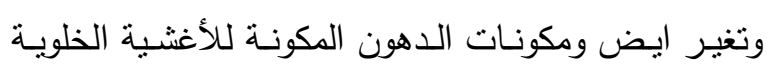

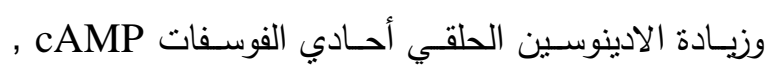

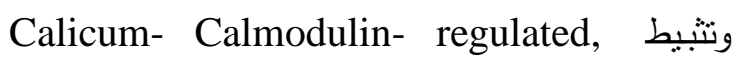
• [17 [16] AMP phosphodiestrase قلويدات عين البزون هي جزئيات كارهة للماء جزئيا لذلك سوف تقحم في طبقتي الدهون في حالة الدهون غير

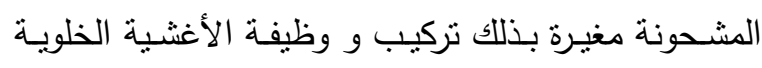

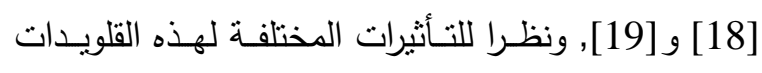

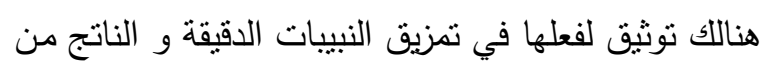

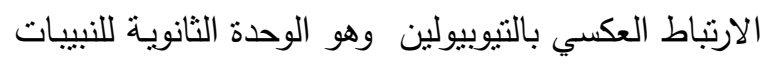

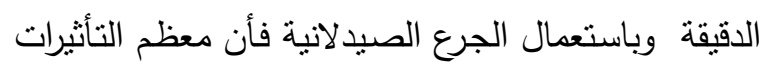

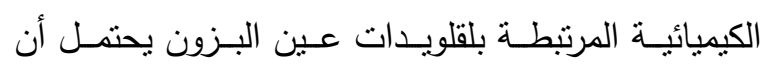

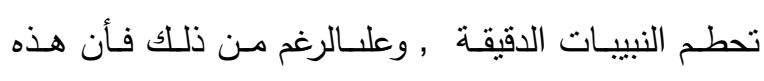
المركبات تحفز التغيرات في طبقة الدهون الثنائية و التي في هني

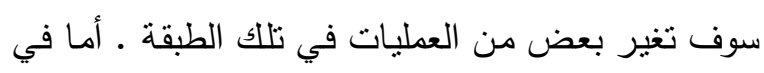

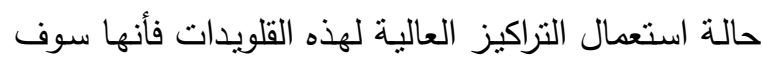

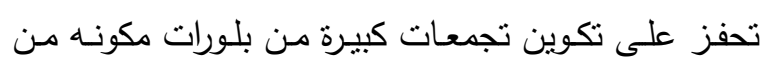

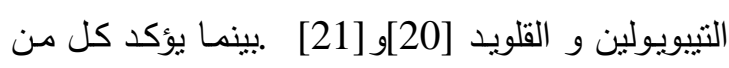

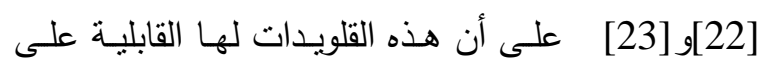

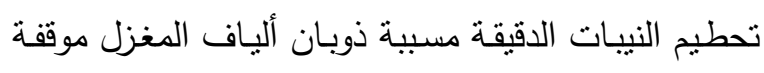

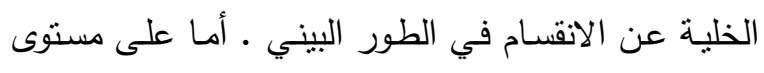

Proliferation Rate(PR)\%= (B/A)x 100

وكالاتي: حيث أن: PR A B: الكثافة الضوئية لمجوعة الاختبار

النتائج و المناقشة

ان معالجة العديد من الإمراض يتطلب اهتماما كبيرا

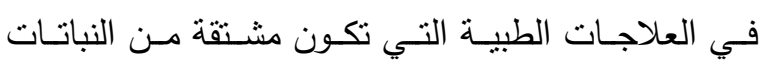
ولاستثنى مـن ذلك معالجـة السرطان ـ استخلصت العديد

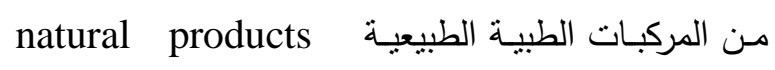
المضادة للسرطان من النباتات ايضاً , وخلافا لما هو علية

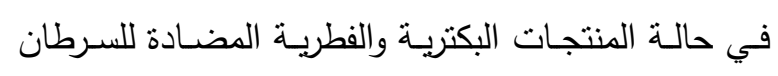

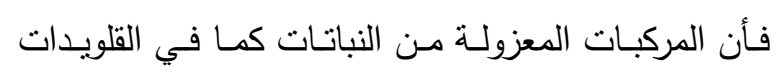
نبـات ال Vinca و Colchicum وبقيـهـ المركبـات الأخرى لاتستهدف الحامض النووي DNA [13] •

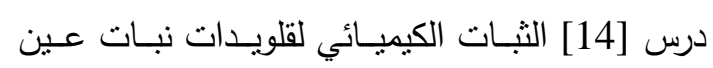

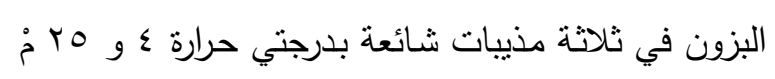

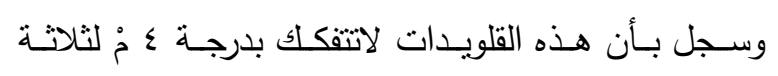

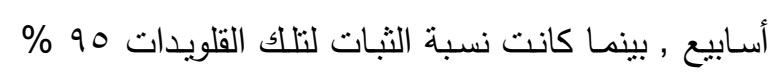
بدرجة حرارة هب مُ لنفس الفترة وهذه الميزة تعطيها أهمية

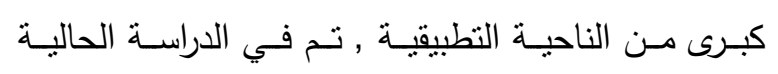

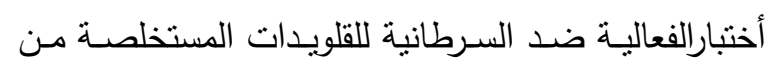
نبات عين البزون C.roseus تجاه نوعين من الخطوط

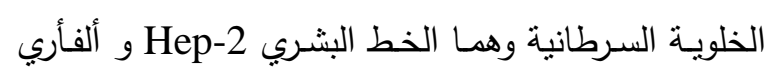
AMN3 وتحفيز الخلايا السرطانية ( IR \% ) و ( PR\% ) على التوالي , وتبين بأن جميع التراكيز المدروسة (م أو 12.5

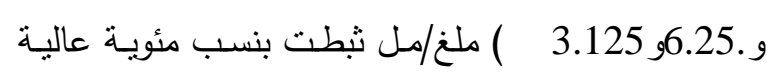
الخط الخلوي السرطاني البشري Hep-2 وذلك من خلال Optical Density ملاحظة الفرق بين الامتصاصية 
التراكيز الستخدمة وكانت الاستجابة قليلة جدا وهذا يؤيد

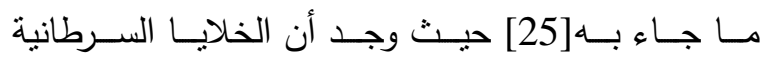

للابيضاض الدم ألفأري P388 كانت مقاومـة لأحد قلويدات عين البزون وعزى ذلك إلى إن مقاومة الخلايا

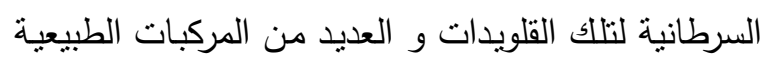
الأخرى المضـادة للسرطان نـاتج عن العديد من آليات الفيات

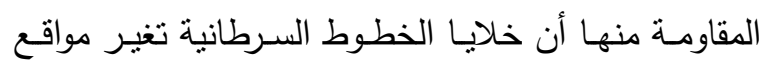
أرتباط نلك القلويدات بالتيوبيولين خلا آلية مبهمة [26] -
دورة الخليـة فـأن القلويدات تثبط الانقسام الخلوي والتي يكون الموقع الابتدائي لفعلها هـو الطور M في دورة الخلية .وتقترح أخر الدراسات إلى أن تحطيم دورة الخلية الخدية قد يؤدي إلى موت الخلية خلال مسار ايضي وتدعى هذه الندان

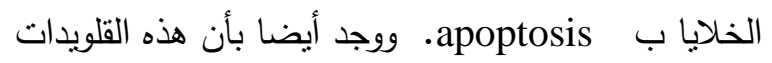
تعدل على تحفيز الخلايـا السـرطانية أن تكون بـالطور

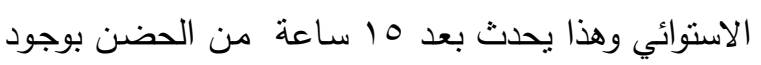

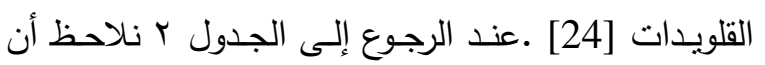

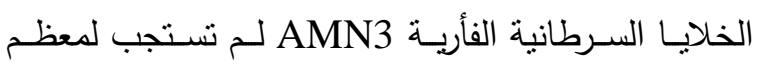

جدول رقم ( ()فعالية القلويدات المستخلصة من نبات عين البزون ضد الخط الخلوي السرطاني البشري .Hep-2

\begin{tabular}{|c|c|c|c|c|}
\hline 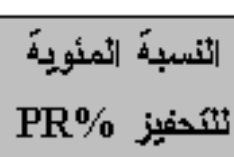 & 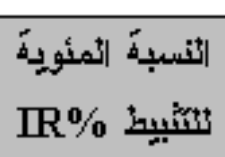 & 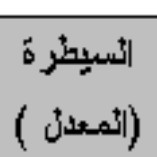 & (أمعـامدز) & 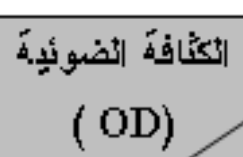 \\
\hline & & & & \\
\hline 12.3 & 87.7 & 0.43 & 0.053 & 25 \\
\hline 11.1 & 88.9 & 0.43 & 0.0476 & 12.5 \\
\hline 11.6 & 88.4 & 0.43 & 0.05 & 6.25 \\
\hline 10.8 & 89.2 & 0.43 & 0.0466 & 3.125 \\
\hline
\end{tabular}

جدول رقم (Y)فعالية القلويدات المستخلصة من نبات عين البزون ضد الخلايا السرطانية الفأرية .AMN

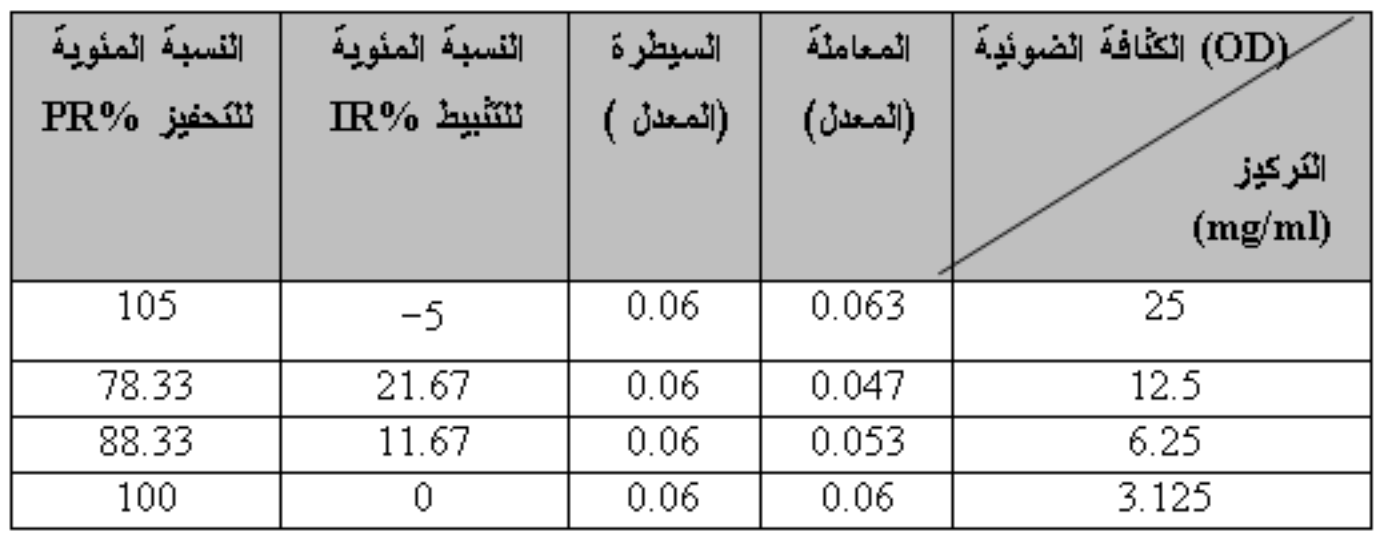




\section{ملحق رقم (1) الوسط الغذائي RPMI-1640}

\begin{tabular}{|c|c|c|c|}
\hline اثكَركيز (غراج /لثئر) & | الثفبكَامبنات | & الثركيز (غراج /لائر) & الأحماض الامبذبة \\
\hline 0.001 & P-Aminobenzoic acid & 0.2 & L-Arginine \\
\hline 0.0001 & D-Biotin & 0.02 & L-Aspartic Acid \\
\hline 0.003 & Choline Chloride & 0.05 & L-Aspargagine \\
\hline 0.000005 & B12 & 0.0625 & L-Cystine. $2 \mathrm{HCl}$ \\
\hline 0.001 & Folic Acid & 0.02 & L-Glutamic Acid \\
\hline 0.035 & Myo-Inositol & 0.3 & L-Glutamine \\
\hline 0.001 & Niacinamide & 0.01 & Glysine \\
\hline 0.00025 & D-Pantothenic Acid.Ca & 0.015 & L-Histidine \\
\hline 0.001 & Pyridoxine. $\mathrm{HCl}$ & 0.02 & Hydroxy-L-proline \\
\hline 0.0002 & Rib oflavin & 0.05 & L-Isoleucine \\
\hline 0.001 & Thiamine . $\mathrm{HCl}$ & 0.05 & L-Leucine \\
\hline التركيز (نر ات /لتر) & مو اذ أخرى & 0.04 & L-Lysine. $\mathrm{HCl}$ \\
\hline 2.0 & D-Glucose & 0.015 & L-Methionine \\
\hline 0.001 & Glutothione & 0.015 & L-phenylalaline \\
\hline 5.96 & HEPES & 0.02 & L-Proline \\
\hline \multirow[t]{5}{*}{0.0053} & Phenol Red,Sodium & 0.03 & L-Serine \\
\hline & & 0.02 & L-Threonine \\
\hline & & 0.005 & L-Tryptophane \\
\hline & & 0.02883 & L-Tyrosine. $2 \mathrm{Na} .2 \mathrm{H} 20$ \\
\hline & & 0.02 & L-Valine \\
\hline
\end{tabular}

4-Nayak, .(2006). Influence of ethanol extract of Vinca rosea on wound in diabetic rats .On line.J.Biol.Sci.,6:40-44.

5-Pearce, H.L. (1990).Medicinal chemistry of bisindole alkaloids from Catharanthus. In: A.B.Orlando(ed.).The alkaloids,vlo, ,37. Academic press.

6-J.B.Harborne, Phytochemical methods, 287,(1973).

7-J.B.Harborne, Phytochemical methods, 287,(1973).

8-J.B.Harborne,Phytochemical methods,287, (1973).
المصنادر

1-Critopoulos,P.(1980). Apocynaceae PP.526542.In: C.C.Townsed and E.Guest (eds)Flora of Iraq vol.4.Robert Maclehose and Co.UK.

2-M.Shoeb,Bang. (2006).Anticancer agent from medicinal plants. Bangladesh J. Pharmocol. ,1:35-41.

3- AL-Rawi, A.,and Chakravarty, H.L. (1988).medicinal plants of Iraq. Ministry of agriculture and irrigation state board for agricultural and water resources research, National Herbarium of Iraq. PP.97. 
chromatography $J$ Chromatogr ., 191: 287.

19-Ter-Minassian-Saraga, L. and Madelmont ,G.(1983). Enhanced hydration of ipalmitoylphosphatidylcholine multibilayer by vinblastine sulphate Biochim Biophys Acta ., 728: 394.

20-Bryan, J.(1972). Vinblastine and microtubules: II. Characterization of two protein subunits from the isolated crystals J. Mol. Biol ., 66: 157.

21-Bensch, K.G. and Malawista, S.E.(1969). Microtubular crystals in mammalian cells J. Cel.1 Biol. , 40: 95.

22-Ter-Minassian-Saraga, L. and Madelmont G.(1983). Enhanced hydration of ipalmitoylphosphatidylcholine

multibilayer by vinblastine sulphate Biochim. Biophys. Acta., 728: 394.

23-Bruchovsky, N., Owen, A.A., Becker, A.J. and Till, J.E.(1965). Effects of vinblastine on the proliferative capacity of L cells and their progress through the division cycle. Cancer Res., 25: 1232.

24-Bruchovsky, N., Owen, A.A. , Becker, A.J. and Till, J.E.(1965). Effects of vinblastine on the proliferative capacity of L cells and their progress through the division cycle. Cancer Res., 25: 1232.

25-Adams, D.J. and Knick, V.C.(1993). MDR and non-MDR forms of cellular resistance to 59-nor-anhydrovinblastine (Navelbine). Proc Am Assoc Cancer Res.,33:462. HE. Taxol as a radiation sensitizer: a flow cytometric study Gynecol. Oncol ., 50: 89.

26-Etievant, C., Barret, J.M. , Kruczynski, A., Perrin, D. and Hill, B.T.(1998). Vinflunine $\quad(20$ ', 20'-difluoro-3' 4'dihydrovinorelbine), a novel Vinca
9-Freshney, R.I. (1994).Culture of animal cells. manual of basic teqnique, pp 440.

10-Freshney, R.I. (2000). Culture of animal cells. manual of basic teqnique PP.566 .

11-Mckeehan, W.L., McKeehan, K.A. , Hammond, S.L.and Ham, R.G.(1994).Improved medium for clonal growth of human diploid cells at low concentrations of serum protein, in vitro,3,399.

12-S.Gao,B.Yu,Y.Li,W.Dong,and H.Luo,World J.Gastroeutrol. , 9,2362, (2003).

13-Beck, W.T., Cass, C.E.and Houghton, P.J.(2000).Microtubule-targeting anticancer drugs derived from plants and microbes .Vinca alkaloids, taxanos and epothilones.

14-Beijnen, J.H., Vendrig, D.E.and Underberg, W.J. (1989).Stability of vinca alkaloids anticancer drugs in three commonly used infusion fluids . Sci., Technol.,43:84-87.

15-Pauwels, O, Kis, R., Pasteel, L.and Atassi, G. (1995). Cytotoxic ,cell kinetics and motphonuclear-induced effects of Vinca alkaloids anticancer agents .J.Pharmpharmacol., 47: 870-875 .

16-Beck, W.T., Cass, C.E.and Houghton, P.J.(2000).Microtubule-targeting anticancer drugs derived from plants and microbes .Vinca alkaloids, taxanos and epothilones.

17-Wilson, L.(1975) . Microtubules as drug receptors: pharmacological properties of microtubule protein Ann $N Y$ Acad. Sci.,253: 213.

18-Kremmer, T. and Holczinger, L.(1980). Investigation of Vinca alkaloid-plasma membrane interactions by detergent gel alkaloid, which participates in P-glycoprotein (Pgp)-mediated multidrug resistance in vivo and in vitro Invest. New Drugs ,16: 3. 


\title{
Anticancer activityof alkaloids of Madagascar Periwinkle Catharanthus roseus (L.)G.Don against two cancer cell line
}
A.A.Shareef
A. A.Y.Al-Mussawi
L. N. Harb
Biology Dept. - Education College - Basrah University

\begin{abstract}
$\underline{\text { Abstract }}$
In the present study, Madagascar Periwinkle Catharanthus roseus (L.)G.Don alkaloids were evaluated against two cancer cell lines :larynx human cancer cell line Hep2, and mouse breast cancer cell line AMN3, by using four concentrations for each cell line $(25,12.5,6,25,3.125) \mathrm{mg} / \mathrm{ml}$ (in triplicate).and it has been found that alkaloids showed highest activity against larynx human cancer cell line Hep-2, while exhibited weak activity against mouse breast cancer cell line AMN3 compared with control treatment.
\end{abstract}

Key words: Catharanthus roseus alkaloids, anticancer activity 